\title{
CORRESPONDENCE.
}

\section{A NEW METHOD OF VALUING POLICIES IN GROUPS,}

To the Editors of the Journal of the Institute of Actwaries.

Dear SIRS,-In accordance with a suggestion by Mr. Lidstone I have tested the application of the method described in the abovementioned paper (J.I.A., April 1920), to the calculation of expected claims.

Applying it to the data of Table I, I have obtained the following results :

Whole-Life Assurances. $\quad$ Expected Claims $\mathrm{O}^{\mathrm{M}}$

$\alpha, \beta$ method.

\begin{tabular}{|c|c|c|c|c|}
\hline \multirow{2}{*}{$\begin{array}{l}\text { Years } \\
\text { of } \\
\text { Birth }\end{array}$} & \multirow{2}{*}{$\begin{array}{c}\text { Age } \\
\text { Grouns }\end{array}$} & \multicolumn{2}{|c|}{ Expected Claims } & \multirow{2}{*}{$\begin{array}{c}\text { Percentage } \\
\text { Deviation }\end{array}$} \\
\hline & & Amount & Deviation & \\
\hline $1823-29$ & $90-96$ & 394 & -1 & $\cdot 25$ \\
\hline $1830-39$ & $80-89$ & 6,337 & -28 & -44 \\
\hline $1840-49$ & $70-79$ & 18,672 & +1 & $\cdot 01$ \\
\hline $1850-59$ & $60-69$ & 18,122 & +6 & .03 \\
\hline $1860-69$ & $50-59$ & 12,003 & +4 & .03 \\
\hline $1870-79$ & $40-49$ & 7,157 & +2 & .03 \\
\hline $1880-89$ & $30-39$ & $\mathbf{3 , 3 8 2}$ & -1 & .03 \\
\hline $1890-98$ & 21-29 & 671 & $\cdots$ & $\cdots$ \\
\hline Total & ... & 66,738 & -17 & $\cdot 03$ \\
\hline
\end{tabular}


I am indebted to Mr. Lidstone for pointing out to me

(1) that if the $\alpha, \beta$ expression for the value be written in the form $\alpha^{\prime} \Sigma+\beta \Sigma^{2}$, where $a^{\prime}=\alpha-4 \cdot 5 \beta$, the multipliers of $a^{\prime}$ and $\beta$ can be obtained by a double summation, the multiplications by 4.5 , \&c., being thereby avoided;

(2) that if the S's are constant, my method will produce accurate results, whatever the values of the $u$ 's.

\section{Yours faithfully,}

\section{H. L. TRACHTENBERG.}

National Institute for Medical Research,

Hampstead, N.W. 3.

11 January 1921. 